\title{
Corpo-temporalidade: a intuição como conhecimento no ensino de teatro ${ }^{1}$
}

Body-temporality: the intuition as knowledge in the teaching drama context

\author{
Juliano Casimiro de Camargo Sampaio
}

Juliano Casimiro de Camargo Sampaio

Professor adjunto doutor da Universidade Federal do Tocantins

1 Este texto é parte dos resultados do projeto de pós-doutoramento realizado pelo autor sob supervisão da Prof.a D.ra Márcia Maria Strazzacappa Hernandez e foi previamente apresentado no Congresso Internacional de Fenomenologia, Educação e Arte da Universidade Federal de São João del Rei.

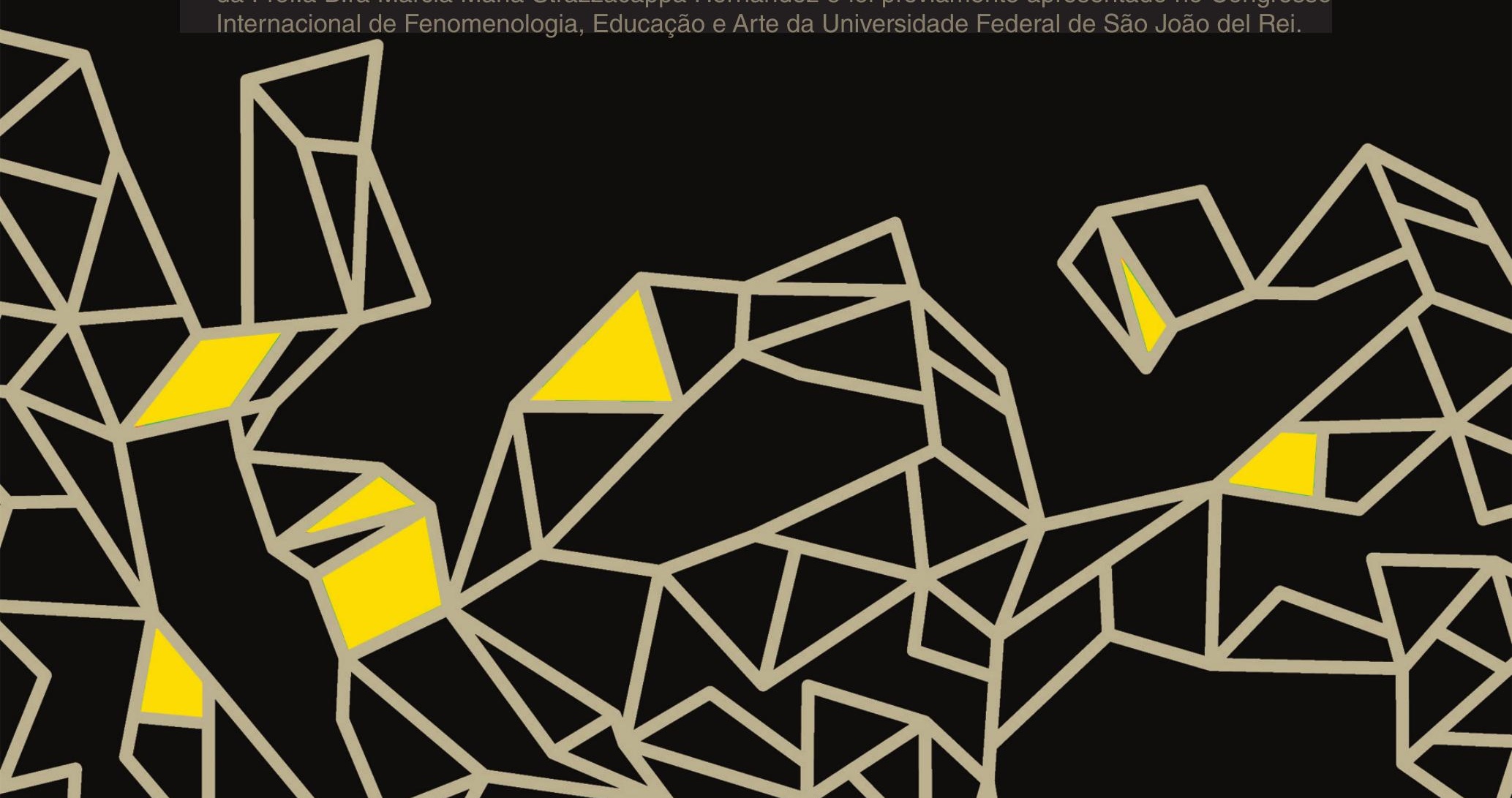




\section{Resumo}

Nossa pesquisa versa sobre as relações entre ensino de teatro, naturezas de conhecimento e duração interior - corpo-temporalidade. Objetivamos de modo mais amplo responder à questão: Como o método da intuição bergsoniana pode nos ajudar a pensar as naturezas de conhecimento no fazer teatral, a partir da reflexão sobre as funções para a inserção do ensino de teatro na educação básica brasileira institucionalizada? Metodologicamente, apresentamos neste texto proposições de natureza teórico-conceitual por meio de revisão crítica da literatura. Em suma, com o método da intuição bergsoniana propomos um deslocamento do foco no ensino de teatro de: 1. apresentação da linguagem teatral para o aluno (contextualização); 2. desenvolvimento do gosto pela linguagem por meio da prática (feitura); 3. formação de espectadores para a linguagem (recepção), - para a experiência da alteridade de si para si mesmo.

Palavras-chave: Bergson, Epistemologia, Experiência estética, Ensino de teatro, Pedagogia teatral.

\section{Abstract}

Our research deals with the relations between drama teaching, natures of knowledge and self's duration - body-temporality. We aim to answer the question: How can the Bergsonian intuition method help us to think of the natures of knowledge in theatrical performance to reflect on functions for the drama teaching insertion in institutionalized Brazilian basic education? Methodologically, we present in this text propositions of a theoretical-conceptual nature, through a critical review of the literature. In short, with the method of Bergsonian intuition, we propose a shift in the focus of the teaching of drama from: 1. presentation of theatrical language to the student (contextualization); 2. development of taste for the language through practice (making); 3 . formation of spectators for the language (reception), - for the experience of the alterity of herself for herself.

Keywords: Bergson, Epistemology, Esthetic experience, Teaching of drama, Theatrical pedagogy. 


\section{Introdução}

Este texto e a pesquisa que o originou se situam na fronteira entre as artes cênicas, a filosofia e a educação, e pretende responder à questão: Como o método da intuição bergsoniana pode nos ajudar a pensar as naturezas de conhecimento no fazer teatral, a partir da reflexão sobre as funções para a inserção do ensino de teatro na educação básica brasileira institucionalizada?

Estamos desde o mestrado buscando caminhos de compreensão das dinâmicas de construção de conhecimento que podem ser disparadas pelas práticas cênicas recorrentes, deslocando nosso foco de investigação da produção artística para o desenvolvimento afetivo-cognitivo de pessoas inseridas em processos de criação. Estamos focados também em investigar como essa inserção pode reorganizar o todo das relações pessoa-mundo (BOESCH, 1991; SAMPAIO, 2016; SIMÃO, 2010).

A escolha pelo método de investigação bergsoniano se deu na medida de nossa suposição inicial, como se verá mais detalhadamente adiante, de que existem frutíferas relações entre a prática teatral na escola e os processos pessoais de construção do corpo enquanto duração e imagem movente de si mesmo (BERGSON, 2005, 2010).

\section{A intuição bergsoniana}

Com fins de que possamos compreender a relevância da questão norteadora da pesquisa para a reflexão acerca do ensino de teatro, precisamos explicitar detidamente o que vem a ser o método intuitivo em Bergson. Após o que faremos articulações possíveis entre esse método e nossas proposições para a inserção do teatro na escola.

A intuição em Bergson, como afirma Deleuze (1999, p. 7), "não é um sentimento nem uma inspiração." Ela é um método rigoroso de conhecimento científico (PINTO, 2010; ZARAGUETA, 1941) que é "essencialmente problematizante (crítica de falsos problemas e invenção de verdadeiros), diferenciante (corte e intersecções) e temporalizante (pensar em termos de duração)" (DELEUZE, 1999, p. 26). Isso porque a intuição opera segundo três regras: 
1. Diferenciação entre problemas verdadeiros e falsos. Os problemas verdadeiros em Bergson (2011) derivam da própria vida, na medida da necessidade de se contornar obstáculos para ação e duração humana. Resumidamente, o autor aponta que os falsos problemas são de dois tipos: a) os inexistentes - porque se organizam, no mais das vezes, em comparações quantitativas (mais e menos); b) os mal formulados - que apresentam mistos de problemas em seus termos, de modo a não poderem ser devidamente analisados.

2. Reconhecimento das verdadeiras diferenciações de naturezas. Trata-se de seguir os caminhos na experiência que permitam reconhecer os pontos focais em que as matérias se revelam diferentes em sua natureza, para depois percorrer as direções em que essas diferentes naturezas se reencontram, já que na experiência a vivência é a do misto.

3. Colocar, aproximar-se de e solucionar problemas em função majoritária de tempo e não de espaço.

Como já explicitado, a experiência do homem no mundo é a do misto (BERGSON, 2010). Pelo método da intuição, a pessoa é capaz de ultrapassar o estado da experiência, do misto, e ir em direção às condições da experiência - naturezas particulares que fazem o misto possível. Ou seja, as condições são constituídas diversamente de acordo com a natureza das coisas que as tornam presentes. Não são gerais ou abstratas, mas dados da própria fonte de experiência. Trata-se de reconhecer fatos que mesmo aparentemente distintos percorrem, em uma espécie de contração, uma mesma "linha" de composição da experiência. São afinidades naturais que permitem que fatos e traços sejam agrupados em uma mesma "linha", enquanto repelem outros tantos no ato de sua contração uns com os outros, formando outras "linhas" constitutivas da mesma experiência.

As "linhas" de contração dos fatos são impelidas para além da própria experiência, mas não em direção às construções abstratas e conceituais (função da inteligência, como explicitaremos mais adiante); ao contrário, são projetadas ao encontro das particularidades e articulações que tornam a experiência uma experiência humana. Em resumo, trata-se de ultrapassar o misto em 
direção às suas particularidades constitutivas - as "linhas" características de cada ação (simbólica), de cada experiência - para que claramente se vejam os pontos de intersecção que nos fazem ter juntas as naturezas constitutivas da experiência, isto é, o modo como elas se apresentam a nós. E nesse aspecto temos o monismo que nos interessa: estudar as naturezas de constituição da experiência (diferenciação) do teatro na escola (suas particularidades composicionais), segundo aspectos característicos da linguagem, mas também do espaço em que a experiência se dá, buscando reconhecer o que lhe é próprio e o que lhe diferencia enquanto experiência (misto) frente às outras atividades desenvolvidas pelos alunos, no que se refere aos processos de constituição da sua corpo-temporalidade (duração atual e virtual da imagem de si mesmo).

A escolha em focar na corpo-temporalidade dos alunos emerge do fato de que apenas a duração (temporalidade) representa um aspecto da natureza dessas "linhas" de contração. O espaço fornece dados para compararmos os elementos da experiência e os próprios mistos entre si, sem que toquemos em aspectos da natureza das particularidades dos mistos (duração). É a partir da duração que, segundo o filósofo, devemos colocar os verdadeiros problemas (filosóficos), oriundos da vida em curso, e extrair daí suas soluções.

Nas palavras de Deleuze (1999), para Bergson:

Quando dividimos alguma coisa conforme suas articulações naturais, temos, em proporções e figuras muito variáveis segundo o caso: de uma parte, o lado espaço, pelo qual a coisa só pode diferir em grau de outras coisas e de si mesma (aumento, diminuição); de outra parte, o lado duração, pelo qual a coisa difere por natureza de todas as outras e de si mesma (alteração). (p. 22, grifos do autor)

Para Bergson (2005) é a partir da própria duração da pessoa, tal como ela é vivida, que se revela a existência de outras durações bastante distintas da própria duração pessoal. E a intuição é, acima de tudo, o movimento pessoal pelo qual se pode ultrapassar a própria duração pessoal em direção às durações das coisas no mundo (Ibid.). Nossa duração nos permite reconhecer e afirmar como distintas as durações de todo o resto com que entramos em contato material ou virtualmente. Nesse sentido, Bergson (2010) parece identificar certa prevalência da duração da pessoa (como ela a vive) nos processos de conhecer, em relação às durações daquilo que se conhece na interação. 
Quando emprega o termo “conhecer", Bergson está falando de uma faculdade natural ao homem, essencialmente voltada para processos de extração daquilo que existe em regularidade e estabilidade na coisa, não em termos de transformação espacial, senão igualmente em termos de duração, sem com isso pretender organizar o mundo material (ZARAGUETA, 1941). Desde essa perspectiva, se é a duração pessoal daquele que conhece que permite conhecer a duração das coisas, conhecer implica antes de tudo acessar as estabilidades e regularidades de si mesmo no tempo (e nisso fazer ver aquilo que varia), a fim de ultrapassar sua própria regularidade em direção à regularidade da coisa. Nesse sentido, conhecer é sempre um conhecer a si mesmo, na medida em que se conhece as coisas. Mas não um conhecer passivo, estático; ao contrário, um conhecer que faz ver movimentos constantes de diferenciação de natureza da coisa em relação a si mesma (alteração) - de si em relação a si mesmo; no nosso caso, os movimentos de diferenciação da corpo-temporalidade daquele que tem experiências em teatro vividas por ele mesmo.

Diante dessa constatação, para Bergson a intuição é a experiência imediata de si mesmo, que não se organiza em termos de espacialidade, nem pela linguagem; é a aceitação da subjetividade em transformação, mas indivisível.

A intuição de que falamos refere-se sobretudo à duração interior. Ela apreende uma sucessão que não é justaposição, um crescimento por dentro, o prolongamento ininterrupto do passado no presente que penetra o futuro. É a visão direta do espírito pelo espírito. Mais nada interposto; nenhuma refração através do prisma cujas faces são o espaço e a linguagem. Em um lugar de estados contíguos a estados, que se tornarão palavras justapostas a palavras, eis a continuidade indivisível, e por isso substancial, do fluxo da vida interior. Intuição significa, pois, primeiramente consciência, mas consciência imediata, visão que quase não se distingue do objeto visto, conhecimento que é contato e mesmo coincidência. (BERGSON, 2006, p. 114)

Bergson (2005) assume, na esteira do que foi exposto, as proposições de Herbert Spencer de que a mudança (alteração) é a substância mesma das coisas. E que toda alteração é ao mesmo tempo uma alteração da matéria e do espírito. Ou seja, se por um lado a duração interior permite o reconhecimento das durações exteriores, o contato com essas últimas, por outro, é sempre em fluxo de mudança da primeira (do si mesmo). Nesse sentido, a duração 
(assim como a memória, que abordaremos mais adiante) precede à intuição. A consciência imediata (intuição) de que fala Bergson (2006) só é possível na medida em que a pessoa e as coisas duram e são fenômenos indivisíveis no tempo. Entretanto, o acesso verdadeiro ao problema e à "realidade" da nossa duração interior, segundo o autor, somente é possível frente aos movimentos intuitivos (BERGSON, 2005). Ou seja, o que o filósofo constrói com essa perspectiva é que a subjetividade humana se dá em termos de temporalidade (realidade que dura), e não em termos de espacialidade (PINTO, 2010). Como afirma Bergson (2011, p. 67), a duração interior nesses termos é "a sucessão de nossos estados de consciência quando nosso eu se deixa livre, quando se abstém de estabelecer uma separação entre o estado presente e os estados anteriores".

Em suma, apenas esse tempo da duração, de que falamos acima, é existente para Bergson (2011): o tempo da sucessão indivisa da existência. Quando isolamos aspectos e fragmentos temporais, criando artificialmente uma intersecção entre espaço e tempo, estabelecemos a artificialidade da "simultaneidade". Para Bergson, portanto, nessas condições a sucessão se torna simultaneidade e se projeta no espaço (PINTO, 2010, p. 24-30).

Ou seja, é a duração interna que permite a existência da simultaneidade, na medida em que podemos isolar instantâneos da duração. Devemos, todavia, atentar para o fato de que trabalhar sob esse prisma não implica lidar com um verdadeiro problema filosófico, já que estaríamos trabalhando em termos de espacialidade (quantitativos) e não de temporalidade (qualitativos). Estaríamos como que nos direcionando para a única realidade homogênea possível, segundo o autor: o espaço, ao passo que a duração interna é completamente heterogênea em relação a si mesma.

Na mesma direção, Bergson (2011) critica ainda a constante tentativa de pensar o mundo como exterior à pessoa em termos de espacialidade. Conforme já apontamos, também os dados externos à subjetividade humana são, segundo o filósofo, constituídos em termos de duração (temporalidade) e não de espacialidade; ainda que construamos nossas linguagens quase sempre em termos de espacialidade. A linguagem no mais das vezes está, segundo o autor, voltada para a representação das coisas (espacialidade) em relação, por exemplo, ao nosso próprio corpo, e não para a construção de 
imagens das coisas (temporalidade) em relação à nossa duração interior. A multiplicidade quantitativa do mundo exterior como conjunto dinâmico (simultaneidade-espaço) é elaborada e vivenciada, nessa perspectiva, enquanto mistos, desde a multiplicidade qualitativa interior (sucessão-duração) (Ibid.).

Para que entendamos o deslocamento proposto pelo autor ao pensar a linguagem - o que nos interessa particularmente por considerarmos, como de costume, o teatro também uma forma de linguagem -, vemos como necessário que se compreenda a passagem da representação para a imagem nas experiências com a matéria e da duração interior. Esse aspecto da teoria bergsoniana influenciou significativamente nossa escolha por trabalhar com e a partir da corpo-temporalidade.

Bergson (2010) defende que a matéria não deve ser pensada em termos de representação, mas como um "conjunto de imagens." Para o filósofo, isso consiste em a matéria possuir características que lhe são próprias e parcialmente percebidas por nós, elaboradas frente à nossa duração. Entretanto, existe um aspecto da condição humana na experiência com o misto que conduz a seletividade no encontro com a matéria: as relações utilitárias. Para Bergson, é comum que pelo critério do útil sejamos enganados na forma como reconhecemos as matérias no mundo: como coisas isoladas com fins específicos e sem relação com as outras matérias a elas contíguas. Esse aspecto nos trai na forma como nos aproximamos, por exemplo, dos movimentos perceptivos. Também eles ficam por essa perspectiva vinculados a elementos comparativos frente às ações de utilidade.

Aos poucos, a constância de algumas ações (inclusive simbólicas) e o arranjo utilitário que fazemos no mundo constroem hábitos, que são em essência de origem representacional (espacial). Ou seja, "nossa representação da matéria é a medida da nossa ação possível sobre os corpos, ela resulta da eliminação do que interessa a nossas necessidades e, de maneira mais geral, nossas funções" (BERGSON, 2010, p. 187-188). E não há problemas para o filósofo que assim nos conduzamos, desde que não tomemos as representações como constituintes da natureza da matéria, de sua imagem. Essa sim, a imagem da matéria, é contígua às demais imagens de matérias ao seu redor; cada imagem continua em outras e vice-versa, e com isso se compõe o todo material. 
Diante desse contíguo de imagens, existe uma que recebe atenção prioritária, segundo Bergson (2010): a "imagem especial" que é nosso corpo, a partir do qual, por meio de relações de contiguidade, estabelecemos as imagens das outras matérias que existem com ele, o corpo.

Vejo bem como as imagens exteriores influem sobre a imagem que chamo meu corpo: elas Ihes transmitem movimento. E vejo também como este corpo influi sobre as imagens exteriores: ele Ihes retribui movimento. Meu corpo é pois, no conjunto do mundo material, uma imagem que age como as outras imagens, recebendo e devolvendo movimento, com esta única diferença, talvez, de que meu corpo parece escolher, em uma certa medida, a maneira de devolver o que recebe. (Ibid., p. 171)

A imagem em Bergson, ao contrário da representação, devolve à matéria e ao corpo a dimensão do "constantemente novo" relacionado à duração. Isso não significa disrupção com algo anterior, pelo contrário, significa atualização do mesmo, da duração. Entre as atividades humanas que mais favorecem esse movimento, para o filósofo, está a arte. Talvez isso aconteça exatamente pelo fato de nossa "imagem especial", o corpo, limitar-nos quanto às relações entre matéria, percepção e memória perante os hábitos construídos ao longo da vida. Não se trata de colocar o corpo como um vilão no que tange às relações com a materialidade; ao contrário, compreendemos que o corpo é a potência, especialmente em arte, que pode estabelecer outras relações para além das utilitárias, ou mesmo, relações utilitárias de outra ordem que não aquela já constituinte dos hábitos pessoais. Nosso corpo é para Bergson (2010) um limite movente.

Vale lembrar que a representação, diretamente associada aos hábitos, se dá por isolamento de aspectos da matéria que atendem a demandas específicas do agente; enquanto a imagem inclui tudo o que está associado às nossas volições e necessidades, mas também aquilo que se mantém obscuro diante delas. É exatamente em contato com essas áreas mais obscuras que nossa "imagem especial" pode fazer emergir a novidade. Novidade que pela contiguidade das imagens é tanto da duração interior (do corpo-temporalidade) quanto da matéria exterior a ela.

Por conseguinte, podemos afirmar que a relação corpo-matéria é, em certo sentido, uma relação de fricção (SAMPAIO, 2016) entre a determinação 
da matéria e a indeterminação do corpo; ao passo que a representação é o encontro da determinação da matéria com aspectos de determinação do corpo, como necessidades e desejos. Nesse sentido, a experiência do misto tende a ser uma experiência da representação, a partir do que podemos chegar às imagens pelo método da intuição apresentado até aqui. Como imagem em caráter de contiguidade, o corpo busca uma diferenciação de si em relação às outras matérias (imagens); enquanto representação, corpo e matéria existem isolados, servindo um ao outro. A diferenciação da "imagem especial", no primeiro caso, constrói-se tanto por ação quanto por afecção. À medida que a percepção está voltada para o exterior, a memória realiza o movimento de trazida do mundo para a duração interior, sendo ela mesma, duração. Em certo sentido, é a memória que retira o corpo da instantaneidade e the atribui duração. Assim, o corpo-temporalidade é o corpo que transita entre a experiência mediada (do hábito e da percepção, por exemplo) e a imediata (da intuição), absolutamente vinculado a uma duração indivisível, garantida em grande medida pela presença da memória.

A passagem da representação à imagem da matéria implica, em Bergson, que deixemos de pensar o movimento (real e/ou imaginado) em termos espaciais. Pensar o movimento em termos espaciais é um ato de isolamento de partes específicas que servem à essa ou àquela finalidade. Também o movimento é da ordem do indivisível, ainda que possamos transpor sua imagem em direção à sua representação. O que não devemos fazer, alerta o filósofo, é tomar o recorte da duração que é o movimento, alocada em uma realidade homogênea (espaço), como a natureza própria do movimento. Para Bergson (2011), pensar o movimento em termos de progresso, daqui para ali, do marco zero ao marco $x$, do tempo zero ao tempo y, é uma ação absolutamente artificial: trata-se de uma síntese mental, um resultado da inteligência. $E$ a inteligência faz com que deixemos de reconhecer "o movimento como ele realmente é, a saber, um ato contínuo e ininterrupto, pura duração" (PINTO, 2010, p. 29).

Acabamos por não reconhecer a verdadeira natureza do movimento pela ação da inteligência, porque, para o autor, o conhecimento intelectual busca a substituição do percebido pelo conceito, da imagem pela representação, do movimento que dura pelo recorte espacial do movimento, e estabelece juízos de relação (espacialidade). Pela inteligência a pessoa tenta organizar o mundo 
material tido como não organizado, a partir do qual e para o qual institui linguagens. Ou seja, o conhecimento intelectual serve-se do mundo em termos de imobilidades ou de mobilidades parciais e nesse sentido se caracteriza por uma natural incompreensão da vida (ZARAGUETA, 1941).

O filósofo alerta ainda que a inteligência não está em estado puro nas funções humanas; outro tipo de conhecimento a interpenetra, mesmo sendo muitas vezes quase anulado por ela: o conhecimento instintivo. Inteligência e instinto são dois modos de operar a matéria, dois caminhos para naturezas diferentes (algumas vezes divergentes) de conhecimento, ambos deficitários em sua essência: a inteligência porque não é capaz de compreender a coisa; o instinto porque apresenta problemas de extensão, de alcance do conhecimento. Diferente do que podemos pensar, o conhecimento instintivo não é para Bergson um simples reflexo, mas a origem das operações imediatas da vida. Quando a inteligência não subsuma o instinto é que se faz possível a presença da intuição. É pela presença do instinto que a intuição resiste ao chamado da inteligência para organizar o mundo e dar primazia ao pensamento. A intuição mantém o mundo em sua desorganização durável e se debruça sobre a ação. Por fim, é possível que desde a intuição se chegue à inteligência voluntariamente, no entanto, da inteligência não se pode chegar à intuição (BERGSON, 2005).

\section{Considerações finais (e o ensino de teatro?)}

Apresentaremos agora a relevância do método da intuição em Bergson para pensar funções para a inserção do teatro na escola, tendo como ponto focal a corpo-temporalidade dos alunos. Nessa direção, é necessário reconhecermos que:

Pensar o ensino de teatro frente a multiplicidade de contextos possíveis de sua inserção me faz supor que deveríamos optar por falar e praticar "ensinos de teatros"; como se o plural pudesse, no mínimo, alertar-nos que não se trata de uma pedagogia única em e para uma área de conhecimento igualmente única, enquanto perspectiva. Sempre que me deparo com professores e alunos, além de artistas, falando da relação entre teatro e escola, na direção das práticas de ensino, um questionamento me toma o corpo: que função e que valia se está pressupondo como base para realizar determinadas naturezas de aproximação do teatro com a escola, na direção do "ensino de teatro"? (SAMPAIO, 2015, p. 1) 
Como explicitamos anteriormente, Bergson (2005) reconhece que o conhecimento intuitivo é característico das artes. Isso não significa, entretanto, que ele seja valorado positivamente nessa área enquanto conhecimento. Consideremos uma vez mais que o conhecimento intuitivo para Bergson é aquele que faz ver a duração interior e sua constante alteração nesse processo (emergência de novidades); levemos em conta também que as artes são as mais intensas experiências humanas em direção a essa natureza de conhecimento. Desde essa perspectiva, não é de estranhar que avancemos nas proposições do autor em direção a afirmar que uma diferença inicial para o ensino de artes (teatro, no nosso caso) em relação a outras disciplinas é que ele possa, pela natureza da sua duração, estar voltado para a duração interior do aluno (corpo-temporalidade) e suas relações com as durações exteriores, e não para a representação (inteligência).

Vale ressaltar, como já apontamos, que o conhecimento intuitivo é bastante vago na vida adulta; e segundo o filósofo, esse é um prejuízo para nossa vida cotidiana, pois limita nossa relação com as matérias e com nossa "imagem-própria", sendo a arte uma das poucas experiências que ainda podem valorizar, pela sua dinâmica contextual, essa natureza de conhecimento. Um segundo ganho provável com o fortalecimento do conhecimento intuitivo, não em detrimento do conhecimento intelectual ou do instintivo, ao contrário, para os equipar em valia, centra-se no que Bergson (2010) reconhece como desenvolvimento. Para o filósofo, o desenvolvimento, inclusive da espécie e não somente de indivíduos específicos, se dá na medida da capacidade do Ser de reconhecer a verdadeira natureza da duração da matéria, fixando-a segundo suas relações sensíveis e mnemônicas com a matéria e usando-a em seu proveito próprio, sem com isso ficar preso aos ditames do conhecimento intelectual: os hábitos. Se o hábito tende a manter as relações com as coisas como estão, a intuição, caminho para o desenvolvimento em Bergson, almeja a emergência da novidade nas regiões mais obscurecidas da relação entre duração interior e duração da matéria.

Compreendemos que o contexto teatral permite à pessoa experimentar o mundo na medida em que testa seu potencial de ação simbólica (BOESCH, 1991) sobre esse mundo, com foco na criação, por estabelecer outros parâmetros de regulação e validação da ação, diversos daqueles da cotidianidade. 
Essa perspectiva de desenvolvimento é possível ao deslocarmos o olhar para as especificidades da experiência no ensino de teatro a fim de chegar às questões pertinentes à corpo-temporalidade (à pessoa, portanto) (SAMPAIO, 2017a). Em suma: reconhecer as "linhas" de contração da experiência para entender no que elas diferem enquanto duração, e depois voltar aos seus pontos de intersecção para ter a experiência enquanto misto que é.

No que se refere à contextualização da pesquisa para a área, estamos claramente buscando a compreensão de um jeito de relacionar teatro e escola distinto daquele que parece ser prioritário no Brasil. Jeito esse que envolve, em síntese, a apresentação da linguagem teatral para o aluno (contextualização), o desenvolvimento do gosto pela linguagem por meio da prática (feitura) e a formação de espectadores para essa linguagem (recepção). Não se trata de criticar esse triângulo, que parece ser pertinente à linguagem em si; trata-se, ao contrário, de evitar reconhecê-lo como a função do teatro na escola, quando é mais provável que contextualização, feitura e recepção sejam dinâmicas do ensino e não sua função propriamente dita. Guardamos, assim, os interesses epistemológicos do ensino de teatro para a alteridade que a pessoa é para si mesma (SAMPAIO, 2017b), a qual pode ser vastamente explorada nas práticas em ensino de teatro, por meio da desobrigação das relações utilitárias e dos hábitos preponderantes nas dinâmicas que primam pelo favorecimento do conhecimento da inteligência e pela dissolução da pessoa frente às demandas sociais, comumente tomadas como mais urgentes. Esse conhecimento, no mais das vezes, relaciona-se a improvisações e construção de cenas, além de outros tipos de explorações da linguagem, que não propiciam ou incentivam a experiência das potencialidades da corpo-duração, da transformação da "imagem especial", como nosso corpo movente é chamado por Bergson.

\section{Referências bibliográficas}

BERGSON, H. A evolução criadora. São Paulo: Martins Fontes, 2005. O pensamento e o movente. São Paulo: Martins Fontes, 2006. Matéria e memória. São Paulo: Martins Fontes, 2010. Ensaios sobre os dados imediatos da consciência. Portugal: Edições 70, 2011. 
$\mathrm{BOESCH}, \mathrm{E}$. Symbolic action theory and cultural psychology. Berlim; Nova York: Heidelberg; Springer, 1991.

DELEUZE, G. Bergsonismo. São Paulo: Editora 34, 1999.

PINTO, T. J. S. O método da intuição em Bergson e sua dimensão ética e pedagógica. São Paulo: Loyola, 2010.

SAMPAIO, J. C. C. A constituição do ser(ator) entre as artes cênicas e a cotidianidade. Palmas: EDUFT, 2017a.

A teatralidade de si mesmo no ensino de teatro. Repertório Teatro e Dança, ano 20 , n. 29, 2017b, p. 233-257.

Que metodologia para que teatro em que escola? Apresentação do Dossiê.

Teatro: Criação e Construção de Conhecimento, Palmas, v. 3, n. 4, p. 1-2, 2015. Teatralidade e narrativa: conhecimento e construção de sentido da experiência criativa. Palmas: Eduft, 2016.

SIMÃO, L. M. Ensaios dialógicos: compartilhamento e diferença nas relações eu-outro. São Paulo: Hucitec, 2010.

ZARAGUETA, J. La intuición en la filosofía de Henri Bergson. Madri: EspasaCalpe, 1941.

Recebido em 27/10/2017

Aprovado em 30/10/2017

Publicado em 29/06/2018 